\title{
The effects of Cosmos caudatus (ulam raja) on dynamic and cellular bone histomorphometry in ovariectomized rats
}

\author{
Norazlina Mohamed $^{1 *}$, Zulaikha Sahhugi ${ }^{3}$, Elvy Suhana Mohd Ramli ${ }^{2}$ and Norliza Muhammad ${ }^{1}$
}

\begin{abstract}
Background: Cosmos caudatus is a local plant which has antioxidant properties and contains high calcium. It is also reported to be able to strengthen the bone. This report is an extension to previously published article in Evidence Based Complementary and Alternative Medicine (doi:10.1155/2012/817814). In this study, we determined the effectiveness of $C$. caudatus as an alternative treatment for osteoporosis due to post-menopause by looking at the dynamic and cellular paramaters of bone histomorphometry.

Methods: Forty female Wistar rats were divided into four groups i.e. sham operated, ovariectomized, ovariectomized treated with calcium $1 \%$ ad libitum and ovariectomized force-fed with $500 \mathrm{mg} / \mathrm{kg} \mathrm{C}$. caudatus extract. Treatment was given six days a week for eight weeks.

Results: Dynamic and cellular histomorphometry parameters were measured. C. caudatus increased double-labeled surface (dLS/BS), mineral appositional rate (MAR), osteoid volume (OV/BV) and osteoblast surface (Ob.S/BS). C. caudatus also gave better results compared to calcium $1 \%$ in the osteoid volume (OV/BV) parameter.

Conclusions: C. caudatus at the $500 \mathrm{mg} / \mathrm{kg}$ dose may be an alternative treatment in restoring bone damage that may occur in post-menopausal women.
\end{abstract}

Keywords: Cosmos caudatus, Osteoporosis, Femur, Bone histomorphometry, Ovariectomized rats

\section{Background}

This paper reported the findings which were an extension to an article recently published [1].

Low bone mass and deterioration of bone tissue microarchitectural which are observed in osteoporosis may eventually lead to increase bone fragility and tendency to fracture $[2,3]$. Osteoporosis has many negative impacts on public health by increasing death rates and economic costs due to the impact of the fracture [2]. Increasing age is a major risk for osteoporosis and fractures [4].

To date, there are several treatments available to treat osteoporosis such as bisphosphonates, calcitonin, estrogen and/or hormone therapy, selective estrogen receptor modulator, anabolic agents and others [5]. However,

\footnotetext{
*Correspondence: azlina@medic.ukm.my

'Department of Pharmacology, Universiti Kebangsaan Malaysia Medical

Center, Jalan Raja Muda Abdul Aziz, 50300, Kuala Lumpur, Malaysia

Full list of author information is available at the end of the article
}

there are many studies reporting that these treatments have side effects such as estrogen treatment can pose risk of breast cancer [6], ovarian and endometrial cancer [7] to the osteoporosis patients even though it can reduce the fracture of hip, vertebrae and other bones [8].

Natural products have been proven to affect bone metabolism by involving a complex balance between deposition, mineralization and resorption of bone matrix [9]. Natural substances that were often studied and were observed to have osteoprotective effects were phytoestrogens such as ferutinin [10], genistein [11] and 8-prenylnaringenin [12].

Cosmos caudatus or better known among locals as ulam raja is a popular herb in Malaysia [13]. Methanol extract of $C$. caudatus was found to have antioxidant activity $[14,15]$. In addition, $C$. caudatus was also found to have antifungal activity [16] and can stimulate bone formation [17]. In analogy with other vegetal substances already demonstrated to mime osteoprotective functions as described above, C. caudatus was considered to be

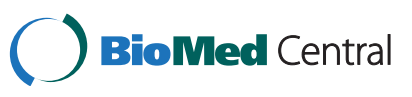


able to act on bone tissue. Thus, this study was done to determine the effects of $C$. caudatus on dynamic and cellular bone histomorphometry of ovariectomized rats which will serve as a model for post-menopausal women.

\section{Methods}

Animals and treatment

This study utilized thirty-two young adult (3 months) female Wistar rats, which were obtained from the Laboratory Animal Resource Unit, Faculty of Medicine, Universiti Kebangsaan Malaysia. The rats, weighing $190 \mathrm{~g}$-260 g, were randomly assigned to four groups with eight rats in each group. Group 1 was sham operated (Sham) while the second group was ovariectomized control group (OVX). The third and fourth groups were ovariectomized and treated with calcium 1\% (Ca) ad libitum and force-fed with $500 \mathrm{mg} / \mathrm{kg}$ C. caudatus extract (CC) respectively. The ovariectomy and sham operation protocol was carried out as previously described [18]. Rats were left recuperating for 1 week before commencing the treatment. Treatment was given six days a week for eight weeks. All rats were injected with two doses of calcein nine days and two days before sacrificed. The study was approved by the Universiti Kebangsaan Malaysia Animal Ethics Committee with the approval code of PP/FAR/2008/NORAZLINA/12-AUGUST/225SEPT-2008-AUG-2009.

\section{Diet, Cosmos caudatus and calcium $1 \%$}

All rats received normal rat chow obtained from Gold Coin, Malaysia. Water extraction method was used to obtain $500 \mathrm{~g} / 300 \mathrm{ml}$ concentration of $C$. caudatus aqueous extract. Extraction was carried out by School of Chemical Sciences \& Food Technology, Faculty of Science and Technology, Universiti Kebangsaan Malaysia as previously described [19]. The $500 \mathrm{mg} / \mathrm{kg}$ dose was prepared by mixing $C$. caudatus with deionized water in ratio $3: 7$. Calcium $1 \%$ solution was prepared by mixing $1 \mathrm{~g}$ of hemicalcium lactic acid (Sigma Chemical CO., USA) with $100 \mathrm{ml}$ deionized water.

\section{Bone histomorphometry}

After 8 weeks of treatment, rats were sacrificed via euthanasia with diethyl ether. The left femora were removed and the distal parts were fixed in $70 \%$ ethanol. Cellular parameters measured were osteoid volume (OV/BS, osteoid volume over bone surface), osteoid surface (OS/BS, osteoid surface over bone surface), osteoclast surface (Oc.S/BS, osteoclast surface over bone surface), osteoblast surface (Ob.S/BS, osteoblast surface over bone surface) and eroded surface (ES/BS, eroded surface over bone surface). Bone samples were decalcified according to the method described by Hermizi et al. [20]. In addition, undecalcified bone samples were used to measure dynamic parameters i.e. single labeled surface (sLS/BS, single labeled surface over bone surface), double-labeled surface (dLS/BS, double-labeled surface over bone surface), mineralized surface (MS/BS, mineralized surface over bone surface), mineral appositional rate (MAR), and bone formation rate (BFR/BS, bone formation rate over bone surface). Preparation of bone samples and measurement techniques were carried out as previously described [20].

\section{Statistical analysis}

All data were subjected to normality test using the Kolmogorov test. For normally distributed data, the statistical test used was analysis of variance, followed by Tukey's honestly significance difference test. While nonnormally distributed data were analysed using MannWhitney and Kruskal Wallis tests. Data analysis was performed using Statistical Package for Social Sciences (18.0.1; SPSS, Inc., Chicago, IL) software. Results were expressed as mean \pm standard error of the mean (SEM).

\section{Results}

Figure 1 shows the photomictorographs of the trabecular bone of the distal part of femurs analysed using fluorescence microscope. Calcein acts as a fluorescent marker which labels the bone surface thus the double-labeled surface (dLS) and single-labeled surface (sLS) parameters may be determined. From the photos, it was observed that the OVX group had more sLS than dLS while the $\mathrm{Ca}$ and $\mathrm{CC}$ groups had more dLS than sLS.

Table 1 shows the dynamic bone histomorphometric results. The $\mathrm{Ca}$ and $\mathrm{CC}$ groups showed significant increase $(\mathrm{p}<0.05)$ in $\mathrm{dLS} / \mathrm{BS}$ compared to the sham group. For mineral appositional rate parameter (MAR), the Ca and CC groups showed a significant increase $(\mathrm{p}<0.05)$ compared to the sham and OVX group.

The results for the cellular parameters are shown in Table 2. The osteoblast surface (Ob.S/BS) of the $\mathrm{Ca}$ and $\mathrm{CC}$ groups were increased significantly $(\mathrm{p}<0.05)$ compared to the OVX group. Osteoid volume (OV/BS) was significantly increased $(\mathrm{p}<0.05)$ in the sham and $\mathrm{CC}$ groups compared to the OVX group. In addition, osteoid volume of $\mathrm{CC}$ group was also higher $(\mathrm{p}<0.05)$ compared to the $\mathrm{Ca}$ group. No significant differences were seen in the other parameters.

\section{Discussion}

Ovariectomy caused a state of estrogen deficiency which may lead to bone loss. The use of rats as a model for postmenopausal osteoporosis has been discussed and significant bone loss may be seen as early as 14 days in the proximal tibial metaphysis [21]. The ovariectomy- 


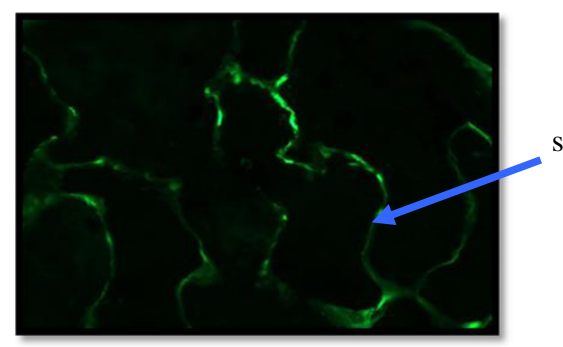

a) Sham group

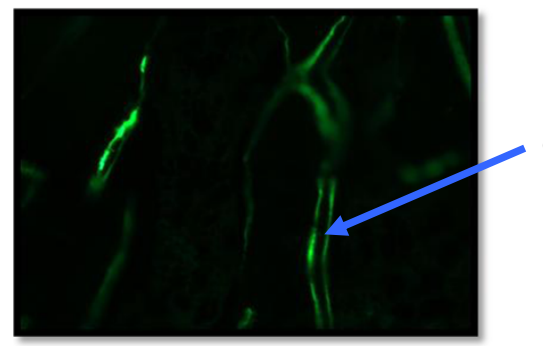

c) Ca group

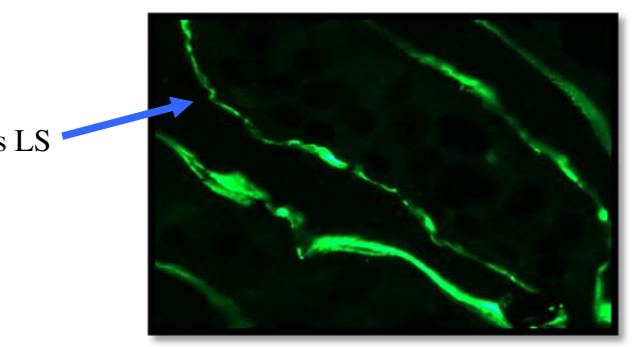

b) OVX group

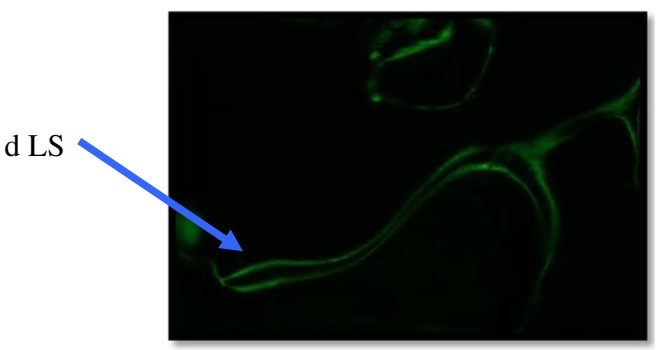

d) CC group

Figure 1 Photomicrographs of trabecular bone labelled with calcein. Arrows indicating dLS (double-labeled surface) and $s L S$ (single-labeled surface).

induced osteopenia observed in rats are similar to skeletal responses in post-menopausal women [22].

In this study, the ovariectomized group did not differ to sham-operated group in terms of dynamic histomorphometry parameters (Table 1). These findings were in agreement with our previous study except in one parameter. The previous study showed that the ovariectomized rats had lower mineral appositional rate compared to the sham-operated group [23]. In terms of cellular histomorphometry parameters, ovariectomy caused reduction in osteoid volume as compared to the sham group. Other parameters were not significantly different compared to sham even though declining values were observed. However, in another study it was observed that cellular parameters deteriorated in the ovariectomized group as compared to the sham group [24]. The discrepancies seen in the histomorphometry parameters between ovariectomized and sham-operated groups were surprising and it may be attributed to the small sample size used in our study. In addition, the technique used in measuring the histomorphometric parameters may not be sensitive since others have found that the use of high-throughput technique such as microcomputed tomography was able to yield more significant results [25].

The effects of $C$. caudatus on bone biochemical markers were previously investigated in which we used the doses of 100, 200 and $300 \mathrm{mg} / \mathrm{kg}$. It was observed that all doses of $C$. caudatus were able to prevent the increase in interleukin-1 and pyridinoline in the ovariectomized group. However, no significant changes were seen

Table 1 The effects of Cosmos caudatus and calcium on dynamic histomorphometry parameters in ovariectomized rats

\begin{tabular}{lcccc}
\hline Dynamic parameters & Sham & OVX & Ca & CC \\
\hline Single labeled surface (\%) & $75.44 \pm 4.00$ & $78.99 \pm 3.35$ & $73.8 \pm 6.33$ & $73.1 \pm 6.33$ \\
Double-labeled surface (\%) & $18.5 \pm 3.33$ & $24.68 \pm 5.08$ & $28.38 \pm 2.78^{*}$ & $38.9 \pm 4.10^{*}$ \\
Mineralized surface (\%) & $58.69 \pm 1.10$ & $63.78 \pm 1.18$ & $60.55 \pm 2.86$ & $63.55 \pm 3.10$ \\
Mineral appositional rate $(\mu \mathrm{m} /$ day) & $1.52 \pm 0.12$ & $1.52 \pm 0.13$ & $3.20 \pm 0.38^{\#^{*}}$ & $3.60 \pm 0.09^{\#^{*}}$ \\
Bone formation rate $\left(\mu \mathrm{m}^{3} / \mu \mathrm{m}^{2} /\right.$ day) & $1.00 \pm 0.09$ & $1.08 \pm 0.02$ & $1.58 \pm 0.27$ & $1.48 \pm 0.29$ \\
\hline
\end{tabular}

Sham sham-operated rats.

OVX ovariectomized rats.

Ca ovariectomized rats supplemented with $1 \%$ calcium.

CC ovariectomized rats supplemented with $500 \mathrm{mg} / \mathrm{kg}$ Cosmos caudatus.

* significant vs sham group $(p<0.05)$.

\# significant vs OVX group $(\mathrm{p}<0.05)$.

Data is presented as mean \pm S.E.M. 
Table 2 The effects of Cosmos caudatus and calcium on cellular histomorphometry parameters in ovariectomized rats

\begin{tabular}{lcccc}
\hline Cellular parameters & Sham & OVX & Ca & CC \\
\hline Osteoblast surface (\%) & $30.92 \pm 8.78$ & $8.75 \pm 5.15^{*}$ & $55.32 \pm 10.2^{\#}$ & $70.4 \pm 7.78^{\#}$ \\
Osteoclast surface (\%) & $52.43 \pm 12.59$ & $65.56 \pm 13.04$ & $62.96 \pm 6.68$ & $36.12 \pm 1.11$ \\
Eroded surface (\%) & $12.32 \pm 6.00$ & $38.89 \pm 14.70$ & $36.53 \pm 9.15$ & $22.62 \pm 4.66$ \\
Osteoid volume (\%) & $13.13 \pm 1.92$ & $4.54 \pm 2.46^{*}$ & $8.66 \pm 1.07$ & $18.27 \pm 0.53^{\# @}$ \\
Osteoid surface (\%) & $72.95 \pm 2.66$ & $51.29 \pm 3.43$ & $63.08 \pm 5.62$ & $71.85 \pm 7.09$ \\
\hline
\end{tabular}

Sham sham-operated rats.

OVX ovariectomized rats.

Ca ovariectomized rats supplemented with $1 \%$ calcium.

CC ovariectomized rats supplemented with $500 \mathrm{mg} / \mathrm{kg}$ Cosmos caudatus.

* significant vs sham group $(\mathrm{p}<0.05)$.

\# significant vs OVX group $(\mathrm{p}<0.05)$.

@ significant vs Ca $1 \%(p<0.05)$.

Data is presented as mean \pm S.E.M.

in the bone histomorphometry parameters (unpublished data).

Following that, we proceeded with a higher dose i.e. $500 \mathrm{mg} / \mathrm{kg}$ and look at the bone histomorphometry paramaters. Parts of the results from this study were previously published in which we observed C. caudatus was able to improve some of the structural bone histomorphometry parameters as compared to ovariectomized group [1]. In this article, we reported the remaining half of the findings i.e. the dynamic and cellular bone histomorphometry parameters.

No significant differences were observed in singlelabeled surface between the treatment groups. High single-labeled surface reflects high bone resorption rate [26]. Thus, the absence of significant differences in this parameter indicates that $\mathrm{Ca} 1 \%$ and $C$. caudatus did not affect the resorption process. However, this study showed that groups treated with $\mathrm{Ca} 1 \%$ and C. caudatus had higher double-labeled surface. The presence of high double-labeled surface indicates high bone formation and active mineralization process $[27,28]$. The results suggested that $500 \mathrm{mg} / \mathrm{kg} \mathrm{C}$. caudatus extract may play a role in stimulating bone formation in ovariectomized rats. Calcium, on the other hand, has been used as a treatment for osteoporosis [29]. Daily calcium supplementation has been shown to prevent bone loss in postmenopausal women [30].

Mineral appositional rate (MAR) is the distance between two fluorescence labels which were formed when calcein was injected on the ninth day and second day before rats were sacrificed [31]. MAR represents the osteoblastic activities in the bone [32]. High MAR value in the $\mathrm{Ca}$ and $\mathrm{CC}$ groups is suggestive of high osteoblastic activity. This is in agreement with osteoblast surface value which was higher in the $\mathrm{Ca}$ and $\mathrm{CC}$ groups compared to OVX.

Osteoid volume (OV/BV) was found to increase significantly in the sham and CC groups compared to the OVX group. The CC group also had a higher osteoid volume compared to the $\mathrm{Ca}$ group. Osteoid is bone matrix that is not mineralized yet. The increase in osteoid volume may occur due to the increase in osteoid formation or by the disruption that has occurred during the process of mineralization of bone [33]. The increase in osteoid volume in the CC group showed that $C$. caudatus may have a role in osteoid formation. This effect of C. caudatus is an advantage over Ca $1 \%$. Cosmos caudatus was found to have high phenolic content of the flavonoids class (which include catechin, epicatechin, myricetin and luteolin) and was observed to possess free-radicals scavenging activity [34]. These properties of C. caudatus may also contribute to its bone-protective effects. It is also reported that C. caudatus contains $270 \mathrm{mg}$ calcium per $100 \mathrm{~g}$ of the plant [35]. This composition, in addition to its antioxidative property, may contribute to the superiority of $C$. caudatus as opposed to calcium supplementation.

Calcium supplementation in this study was given in drinking water at the concentration of $1 \%$. This method of administration was used in our previous study [36] and has also been used by others [37]. The advantage of using this route of administration is that it minimizes the stress from using injection or oral gavage. However we did not measure serum levels of calcium to ensure adequate calcium intake which can further verify the differences seen between the $C$. caudatus group and the $\mathrm{Ca}$ $1 \%$ group.

No significant differences in osteoid surface (OS/BS) were observed between all the groups. Although the percentage of osteoid surface is higher in the $\mathrm{Ca}$ and $\mathrm{CC}$ groups than in the OVX group, significant difference was not observed. This may be attributed to the small sample size used in this study.

There were no significant differences in osteoclast surface (Oc.S/BS) between all the groups. However, based on a previous study, there was a significant increase in Oc.S/BS for ovariectomized rats [38]. In addition, postmenopausal condition can stimulate the formation of 
osteoclast by the production of nuclear factor- $\mathrm{k} \beta$ ligand (RANKL) and tumor necrosis factor (TNF) by monocytes and $\mathrm{T}$ cell, and this phenomenon tends to occur in women with osteoporosis [39]. C. caudatus did not seem to cause any effects on osteoclast surface which implies C. caudatus has no effects on resorption process.

\section{Conclusions}

C. caudatus has beneficial effects on dynamic and celluar bone histomorphometry parameters in ovariectomized rats. C. caudatus was also observed to be superior to $\mathrm{Ca}$ $1 \%$ in increasing the osteoid volume parameter. Thus, $C$. caudatus has the potential to become an alternative treatment in restoring bone damage in post-menopausal women.

\section{Competing interests}

The authors declare that they have no competing interests.

\section{Authors' contributions}

NM participated in the design of the study and drafted the manuscript. ZS carried out the analysis and performed the statistical analysis. ESMR participated in interpreting the bone histomorphometry analysis. NM helped in the design of the study and helped to draft the manuscript. All authors read and approved the final manuscript.

\section{Acknowledgments}

The authors are grateful to Prof Dr Abdul Salam Babji from Faculty of Science and Technology, Universiti Kebangsaan Malaysia for the preparation of the plant extract. The authors thank Ms. Azizah Osman, Ms. Sinar Suriya Muhamad, Mr. Arizi Aziz, Ms. Mazliadiyana Mazlan, Mr. OK Azuan Ghazali and Mr. Imran Mohd Ali for their technical assistance. The authors expressed their gratitude to UKM grant FF-193-2008 for funding this project.

\section{Author details}

'Department of Pharmacology, Universiti Kebangsaan Malaysia Medical Center, Jalan Raja Muda Abdul Aziz, 50300, Kuala Lumpur, Malaysia. ${ }^{2}$ Department of Anatomy, Universiti Kebangsaan Malaysia Medical Center, Kuala Lumpur, Malaysia. ${ }^{3}$ Department of Biomedical Sciences, Faculty of Health Sciences, Kuala Lumpur, Malaysia.

Received: 7 February 2013 Accepted: 21 June 2013

Published: 24 June 2013

\section{References}

1. Mohamed N, Gwee Sian Khee S, Shuid AN, Muhammad N, Suhaimi F, Othman F, Babji AS, Soelaiman IN: The effects of Cosmos caudatus on structural bone histomorphometry in ovariectomized rats. Evid Based Complement Alternat Med 2012, 2012:817814.

2. Rong SY, Shing H: Current pharmacological approaches to prevent and treat post menopausal osteoporosis. Recent Pat Endocr Metab Immune Drug Discov 2009, 3:42-53.

3. Consensus Development Conference: Diagnosis, prophylaxis and treatment of osteoporosis. Am J Med 1993, 94:646-650.

4. Cooper C, Campion G, Melton LJ: Hip fractures in the elderly: a world-wide projection. Osteoporosis Int 1992, 2(6):285-289.

5. Mühlbauer RC, Li F: Nutrition: effect of vegetables on bone metabolism. Nature 1999, 401:343-344.

6. Ross RK, Paganini-Hill A, Wan PG, Pike MC: Effect of hormone replacement therapy on breast cancer risk: Estrogen versus estrogen plus progestin. J Natl Cancer Inst 2000, 92:328-332.

7. Davison S, Davis SR: Hormone replacement therapy: current controversies. Clin Endocrinol 2003, 58:249-261.

8. Anderson $\mathrm{GL}$, Limacher $\mathrm{M}$, Assaf AR: Effects of conjugated equine estrogen in postmenopausal women with hysterectomy: the Women's health initiative randomized controlled trial. J Am Med Assoc 2004, 291(14):1701-1712.
9. Putnam SE, Scutt AM, Bicknell K, Priestley CM, Williamson EM: Natural products as alternative treatments for metabolic bone disorders and for maintenance of bone health. Phytother Res 2007, 21:99-112.

10. Ferretti M, Bertoni L, Cavani F, Zavatti M, Resca E, Carnevale G, Benelli A, Zanoli P, Palumbo C: Influence of ferutinin on bone metabolism in ovariectomized rats. II: role in recovering osteoporosis. J Anat 2010, 217:48-56.

11. Setchell KD, Lydeking-Olsen E: Dietary phytoestrogens and their effect on bone: evidence from in vitro and in vivo, human observational, and dietary intervention studies. Am J Clin Nutr 2003, 78(3 Suppl):593S-609S.

12. Hümpel M, Isaksson $P$, Schaefer $O$, Kaufmann U, Ciana P, Maggi A, Schleuning WD: Tissue specificity of 8-prenylnaringenin: protection from ovariectomy induced bone loss with minimal trophic effects on the uterus. J Steroid Biochem Mol Biol 2005, 97:299-305.

13. Ong HC, Norzalina J: Malay herbal medicine in Germencheh Negeri Sembilan, Malaysia. Fitoterapia 1999, 70:10-14.

14. Andarwulan N, Batari R, Sandrasari DA, Bolling B, Wijaya H: Flavonoid content and antioxidant activity of vegetables from Indonesia. Food Chem 2010, 121(4):1231-1235.

15. Huda-Faujan N, Noriham A, Norrakiah AS, Babji AS: Antioxidant activity of plants methanolic extracts containing phenolic compounds. Afr J Biotechnol 2009, 8(3):484-489.

16. Fuzzati N, Sutarjadi, Dyatmiko W, Rahman A, Hostettmann K: Phenylpropane derivates from roots of Cosmos caudatus. Phytochem 1995, 39:409-412.

17. Ismail S: Sayuran Tradisional Ulam dan Penyedap Rasa. Bangi: Universiti Kebangsaan Malaysia; 2000.

18. Shuid AN, Mohamad S, Mohamed N, Mokhtar SA, Muhammad N, Soelaiman IN: Bone oxidative changes during early fracture healing of postmenopausal osteoporosis rat model. Asian J Animal Vet Adv 2011, 6:1193-1203.

19. Huda-Faujan N, Norihan A, Norrakiah AS, Babji AS: Antioxidative activities of some Malaysian herbal water extracts. ASEAN Food J 2007, 14:61-68.

20. Hapidin H, Othman F, Soelaiman IN, Shuid AN, Mohamed N: Effects of nicotine administration and nicotine cessation on bone histomorphometry and bone biomarkers in Sprague-Dawley male rats. Calcif Tissue Int 2011, 88:41-47.

21. Lelovas PP, Xanthos TT, Thoma SE, Lyritis GP, Dontas IA: The laboratory rat as an animal model for osteoporosis research. Comp Med 2008, 58(5):424-430

22. Mosekilde L: Assessing bone quality-animal models in preclinical osteoporosis research. Bone 1995, 17:343S-352S.

23. Aktifanus AT, Shuid AN, Rashid NHA, Ling TH, Loong CY, Saat NM, Muhammad N, Mohamed N, Soelaiman IN: Comparison of the effects of tocotrienol and estrogen on the bone markers and dynamic changes in postmenopausal osteoporosis rat model. Asian J Anim Vet Adv 2012, 7:225-234.

24. Fathilah SN, Nazrun Shuid A, Mohamed N, Muhammad N, Nirwana Soelaiman I: Labisia pumila protects the bone of estrogen-deficient rat model: a histomorphometric study. J Ethnopharmacol 2012, 142(1):294-299.

25. Xiang A, Kanematsu M, Mitamura M, Kikkawa H, Asano S, Kinoshita M: Analysis of change patterns of microcomputed tomography 3dimensional bone parameters as a high-throughput tool to evaluate antiosteoporotic effects of agents at an early stage of ovariectomyinduced osteoporosis in mice. Invest Radiol 2006, 41(9):704-712.

26. Woods AE, Ellis RC: Laboratory histopathology: a complete reference. London: Churchill Livingstone Publisher; 1994.

27. Hapidin H, Othman F, Soelaiman IN, Shuid AN, Mohamed N: Beneficial effects of tocotrienol and tocopherol on bone histomorphometric parameters in sprague-dawley male rats after nicotine cessation. Calcif Tissue Int 2009, 84:65-74.

28. Ahmad NS, Khalid BAK, Luke DA, Ima-Nirwana S: Tocotrienol offers better protection than tocopherol from free radical-induced damage of rat bone. Clin Exp Pharmacol Physiol 2005, 32:761-770.

29. Gass M, Dawson-Hughes B: Preventing osteoporosis-related fractures: an overview. Am J Med 2006, 119:S3-S11.

30. Nordin BEC: The effect of calcium supplementation on bone loss in 32 controlled trials in postmenopausal women. Osteoporosis Int 2009, 20(12):2135-2143. 
31. Parfitt AM, Drezner MK, Glorieux FH, Kanis JA, Malluche $H$, Meuner PJ, Ott SM, Recker RR: Bone histomorphometry: standardization of nomenclature, symbols and units. J Bone Miner Res 1987, 6:595-610.

32. Frost HM: Bone histomorphometry: analysis of trabecular bone dynamic. In Bone histomorphometry: technique and interpretations. Edited by Recker R. Boca Raton: CRC Press; 1983:109-131.

33. Turner CH, Owan I, Brizendine EJ, Zhang W, Wilson ME, Dunipace AJ: High fluoride intake causes osteomalacia and diminished bone strength in rats with renal deficiency. Bone 1996, 19:595-601.

34. Mustafa RA, Abdul Hamid A, Mohamed S, Bakar FA: Total phenolic compounds, flavonoids, and radical scavenging activity of 21 selected tropical plants. J Food Sci 2010, 75(1):C28-C35.

35. Nutriweb Malaysia: nutrition composition database - ulam raja. http://www.nutriweb.org.my/cgi-bin/dbrecords.cgi? comp=Minerals\&submit_do=View\&food_no $=105105 \&$ part1 $=$ Raw + and + Processed\&fname $=U$ lam+raja\&group=Vegetables\&mname=Ulam+raja.

36. Cho JH, Cho DC, Yu SH, Jeon YH, Sung JK, Kim KT: Effect of dietary calcium on spinal bone fusion in an ovariectomized rat model. $J$ Korean Neurosurg Soc 2012, 52(4):281-287.

37. Shuid AN, Mohamad S, Mohamed N, Fadzilah FM, Mokhtar SA, Abdullah S, Othman F, Suhaimi F, Muhammad N, Soelaiman IN: Effects of calcium supplements on fracture healing in a rat osteoporotic model. J Orthop Res 2010, 28(12):1651-1656.

38. Wronski TJ, Walsh CC, Ignaszewski LA: Histologic evidence for osteopenia and increased bone turnover in ovariectomized rats. Bone 1986, 7(2):119-123.

39. D'Amelio P, Grimaldi A, Di Bella S, Brianza SZM, Cristofaro MA, Tamone C, Giribaldi G, Ulliers D, Pescarmona GP, Isaia G: Estrogen deficiency increases osteoclastogenesis up-regulating $T$ cells activity: a key mechanism in osteoporosis. Bone 2008, 43(1):92-100.

doi:10.1186/1756-0500-6-239

Cite this article as: Mohamed et al:: The effects of Cosmos caudatus

(ulam raja) on dynamic and cellular bone histomorphometry

in ovariectomized rats. BMC Research Notes 2013 6:239.

\section{Submit your next manuscript to BioMed Central and take full advantage of:}

- Convenient online submission

- Thorough peer review

- No space constraints or color figure charges

- Immediate publication on acceptance

- Inclusion in PubMed, CAS, Scopus and Google Scholar

- Research which is freely available for redistribution 